(C) 2017. This manuscript version is made available under the CC-BY-NC-ND 4.0 license http://creativecommons.org/licenses/by-nc-nd/4.0/

\title{
Effect of load and meshing stiffness variation on modal properties of planetary gear
}

\section{Ayoub Mbarek ${ }^{\mathrm{a}, \mathrm{b}}$,Ahmed Hammami ${ }^{\mathrm{a}}$,Alfonso Fernandez Del Rincon ${ }^{\mathrm{b}}$,Fakher Chaari $^{\mathrm{a}}$,Fernando Viadero Rueda ${ }^{\mathrm{b}}$,Mohamed Haddar ${ }^{\mathrm{a}}$}

ayoubmbarekenit@gmail.com, ahmed.hammami2109@gmail.com, alfonso.fernandez@unican.es, fakher.chaari@gmail.com, fernando.viadero@unican.es, mohamed.haddar@enis.rnu.tn

${ }^{a}$ Mechanics, Modeling and Production Laboratory, National School of Engineers Sfax, BP 1173, 3038 Sfax, Tunisia

${ }^{\mathrm{b}}$ Department of Structural and Mechanical Engineering, Faculty of Industrial and Telecommunications Engineering, University of Cantabria, Avda. de losCastros s/n, 39005 Santander, Spain

\begin{abstract}
Modal analysis of mechanical transmissions allows identification of critical frequencies and corresponding vibration modes. Major research works are done under constant loading conditions. However, load fluctuation can lead to variability in stiffness characteristics. Also, in the case of gear transmission, the fluctuation of mesh stiffness is rarely considered in the modal analysis. In this paper, a modal analysis of planetary gear transmission is investigated for different loading conditions and under mesh stiffness fluctuation. Hammer impact tests are carried out and the vibrations on fix ring are measured with different levels of load. During each test, natural frequencies are identified through frequency response function. The obtained results are correlated against the corresponding tridimensional lumped parameter of the test rig. Distributions of modal strain and kinetic energy for different loading conditions are studied as well as the effect of mesh stiffness variation on the natural frequencies.
\end{abstract}

Keywords: modal analysis, natural frequency, tridimensional lumped parameter, modal energy, mesh stiffness.

\begin{tabular}{ll|}
\hline Nomenclature & The ring-planet mesh stiffness \\
$\mathrm{K}_{r p}$ & The sun-planet mesh stiffness \\
$\mathrm{K}_{s p}$ & The carrier 's shaft flexural stiffness \\
$\mathrm{k}_{\mathrm{cf}}$ & The sun 's shaft flexural stiffness \\
$\mathrm{k}_{\mathrm{sf}}$ & The carrier 's shaft torsional stiffness \\
$\mathrm{k}_{\mathrm{ct}}$ & The sun 's shaft torsional stiffness \\
$\mathrm{k}_{\mathrm{st}}$ & The carrier 's shaft axial stiffness \\
$\mathrm{k}_{\mathrm{ca}}$ & The sun 's shaft axial stiffness \\
$\mathrm{k}_{\mathrm{sa}}$ & Natural pulsations \\
$\omega_{i}$ &
\end{tabular}




\begin{tabular}{|ll|}
\hline$\varphi_{\mathrm{i}}$ & Vibrations modes \\
$\mathrm{q}$ & Degree of freedom vector \\
$\mathrm{M}$ & Global mass matrix \\
$\mathrm{K}_{\mathrm{b}}$ & Bearing stiffness matrix \\
$\mathrm{K}_{\mathrm{e}}(\mathrm{t})$ & Time varying mesh stiffness matrix \\
$\mathrm{K}_{\mathrm{c}}$ & Coupled matrix \\
$\mathrm{C}$ & Damping matrix \\
$\mathrm{F}(\mathrm{t})$ & External force vector \\
$\psi_{\mathrm{r}}$ & Pressure angle of the ring-planet \\
$\psi_{\mathrm{s}}$ & Pressure angle of the sun-planet \\
$\alpha_{\mathrm{i}}$ & Angular position of planet $\mathrm{i}$ \\
$\alpha_{\mathrm{s}}$ & Pressure angle of the sun \\
$\alpha_{\mathrm{r}}$ & Pressure angle of the ring \\
$\mathrm{R}_{\mathrm{br}}$ & Base radius of the rings \\
$\mathrm{R}_{\mathrm{bs}}$ & Base radius of the suns \\
$\mathrm{R}_{\mathrm{bp}}$ & Base radius of the planets \\
$\mathrm{m}_{i j}$ & Masses of component iof gear $\mathrm{j}$ \\
$\mathrm{I}_{i j}$ & Inertia of component iof gear $\mathrm{j}$ \\
$\mathrm{K}_{i j k}$ & Bearing stiffnessof component iof gear $\mathrm{j}$ in k direction \\
\hline
\end{tabular}

\section{1-Introduction:}

Planetary gears are used frequently in different industrial applications like wind turbine and automotive because of their substantial advantages such as their abilty to transmit high power in compact environment. However, planetary gears have some drawbacks such as noise and vibration, especially close to critical resonant frequencies. For this reason, many models have been developed in order to identify the modal proprieties of planetary gear.

Most of the studies used lumped-parameters models to determine vibration characteristics of planetary gears with several configurations. A great majority of them was either purely torsional or two-dimensional. Cunliffe et al. [1] focused on a mathematical model of a planetary gear with fixed carrier and identified vibration modes from experimental test rig. Lin and Parker [2] identified proprieties of natural frequencies and vibration modes as well as their sensitivity to parameters of planetary gear with four planets. August and Kasuba [3] investigated a lumped parameters model with nine degrees of freedom in order to analyse vibration of simple planetary gear. Abousouleiman and Velex [4] developed a tridimensional model combining finite elements and lumped parameter models. Ambarisha and Parker [5] used finite elements model to analyse planetary gear dynamics and validated their analytical lumped- 
parameter model. Lin and Parker [6] used a bi-dimensional lumped parameter planetary gear to study modal proprieties of planetary gear with equally spaced planets. Hammami et al. [7] used a bi-dimensional lumped parameter model of back to back planetary spur gear to study modal characteristics through determination of kinetic and strain energy.

However, few studies of three-dimensional lumped parameter models exist in literature. We can find the model of Eritenel and Parker [8] which is a three dimensional one dedicated to the study of modal proprieties. Furthermore, other models consider the nonlinearity [9,10],the gyroscopic effect $[11,12]$ and the non stationary conditions [13,14].Mesh stiffness is an important parameter in planetary gear modelling, it was always considered in the modelling process. For example, Kahraman [15], established an analytical model including a variable meshing stiffness. Also, Velex and Flamand [16] proved that mesh stiffness is an important parameter acting on natural frequency by using tridimensional model of planetary gear. Gelman[17] used a piecewise linear technique for spur gear model in order to estimate the damping ratio and the natural frequency. However, the majority of these works consider mean values of the mesh stiffness when computing the natural frequencies

Correlation between numerical and experimental modal analysis was not extensively studied for planetary gears. Ericson and Parker [18] used experimental modal analysis techniques to characterize the dynamic behavior of spur planetary gears and compared these results with those issued from lumped parameters and finite elements models. Kahraman and Vijayakar [19] investigated the effect of internal gear flexibility under the quasi-static condition behaviour of a planetary gear set. Toda and Botman [20] showed experimentally that planetary gear vibration resulting from the planet position error can be minimized by a proper indexing planet.

Few studies were devoted to the influence of loading conditions on modal properties of gear transmissions. Ericson and Parker [21] studied the effect of torque on parameter of planetary gears; they validated their experimental results by analytical and finite element model.

In this paper, an experimental modal analysis of planetary gear with variable loading conditions and correlation with three-dimensional lumped parameters model is conduced. Effects of varying mesh stiffness and load are investigated.

\section{2-Experimental setup:}




\section{2-1-Description of test bench:}

Experimental impact tests are achieved on a test bench developed at the University of Cantabria in Spain. The test bench consists of a planetary reaction gear with a free ring and a planetary test gear with fixed ring. The two-planetary gear are mounted back to back so that the circulation of power are done through transmission, this composition is chosen in order to minimize costs and improve energy efficiency. The planetary gears are identical and are driven by an electric motor. They are connected to each other by means of two rigid shafts linking suns and carriers, the inner one is called sun shaft and external shaft is called carrier shaft. The references [7,22,23] presented more details concerning this test bench.

The external load is obtained by adding various masses on the arm which is attached to reaction gear (figure 1).

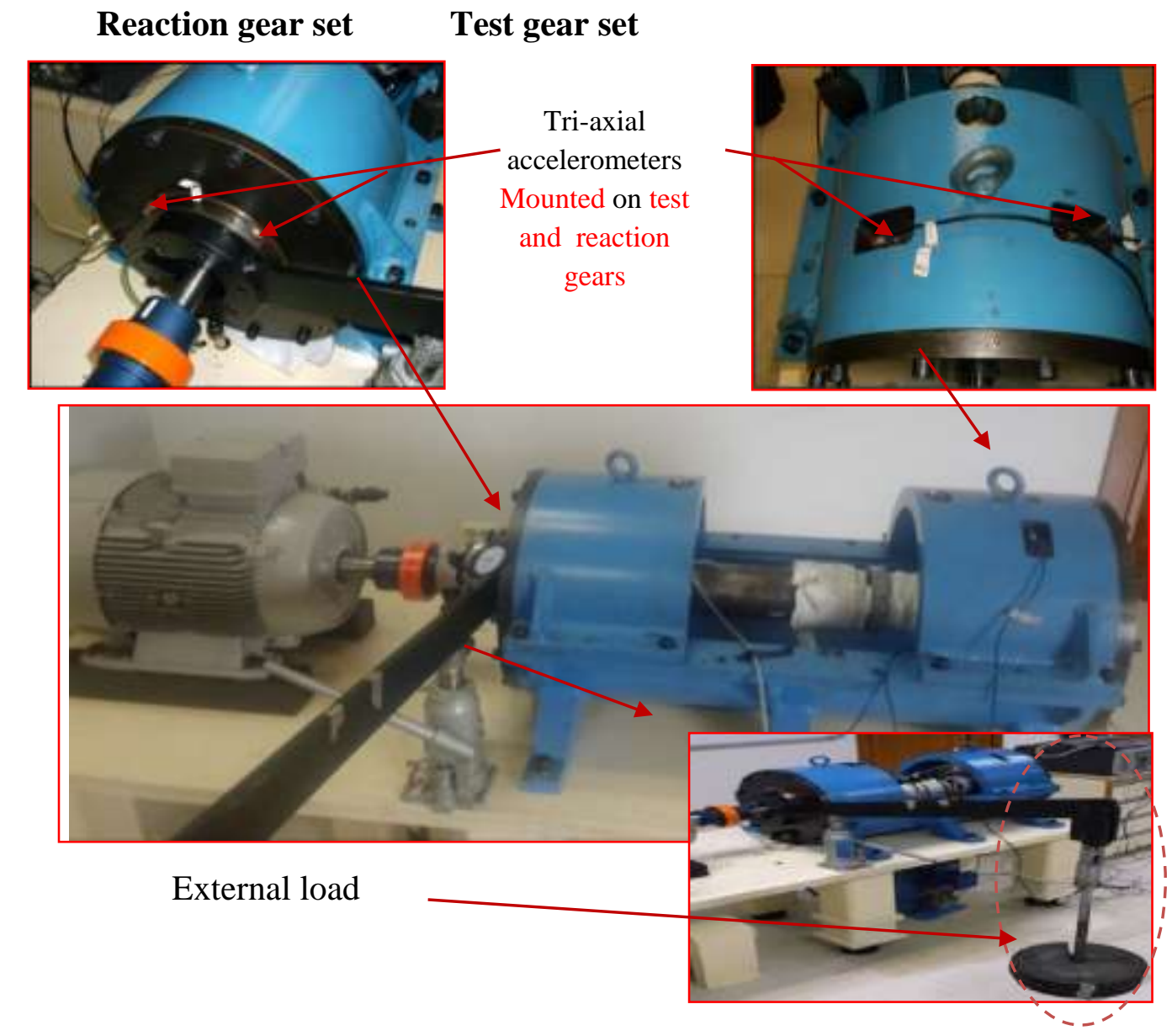

Figure 1: Experimental planetary gear test bench

\section{2-3-Data acquisition and processing:}

Tri-axial accelerometers are mounted on fix ring and free ring in order to measure the accelerations of rings. 
The signals coming from accelerometers will be processed with the software "LMS Test.Lab signature acquisition" to obtain the frequency response function.

\section{3-Planetary gear numerical model:}

Figure (2) shows the numerical model referred to test bench. It is a three-dimensional lumped parameter model characterised by 6 degrees of freedom per component based on the work done by Karray et al [24].

This model is composed of two planetary gear sets: reaction planetary gear set (r) and test planetary gear set (t). Each stage is composed of the ring (r) the carrier (c), the sun (s)and three planets(p1, p2, p3). These components are modelled as rigid bodies with massm $_{i j}$, inertiaI $i j$. Each components is supported by bearing with stiffness $\mathrm{k}_{i j k}$ where $\mathrm{i}=\mathrm{c}, \mathrm{r}, \mathrm{s}, \mathrm{p} 1, \mathrm{p} 2, \mathrm{p} 3$;j=r,tin direction $\mathrm{k}=\mathrm{x}, \mathrm{y}, \mathrm{z}, \phi, \Psi, \theta$

The sun and the ring are connected respectively to the planets through the gear mesh stiffness $\mathrm{K}_{r p r l}, \mathrm{~K}_{r p r 2}, \mathrm{~K}_{r p r 3}$ and $\mathrm{K}_{s p r 1}, \mathrm{~K}_{s p r 2}, \mathrm{~K}_{s p r 3}$ in the reaction gear set and through the gear mesh stiffness $\mathrm{K}_{r p t 1}, \mathrm{~K}_{r p t 2}, \mathrm{~K}_{r p t 3}$ and $\mathrm{K}_{s p t 1}, \mathrm{~K}_{s p t 2}, \mathrm{~K}_{s p t 3}$ in the test gear set. The two planetary gear sets are connected through sun's shaft and carrier's shaft. Each shaft is characterized respectively by axial stiffness $\mathrm{k}_{\text {saand }} \mathrm{k}_{\mathrm{ca}}$;flexural stiffness $\mathrm{k}_{\text {sfandkf }}$ and torsional stiffnessks tand $\mathrm{k}_{\mathrm{ct}}$. 


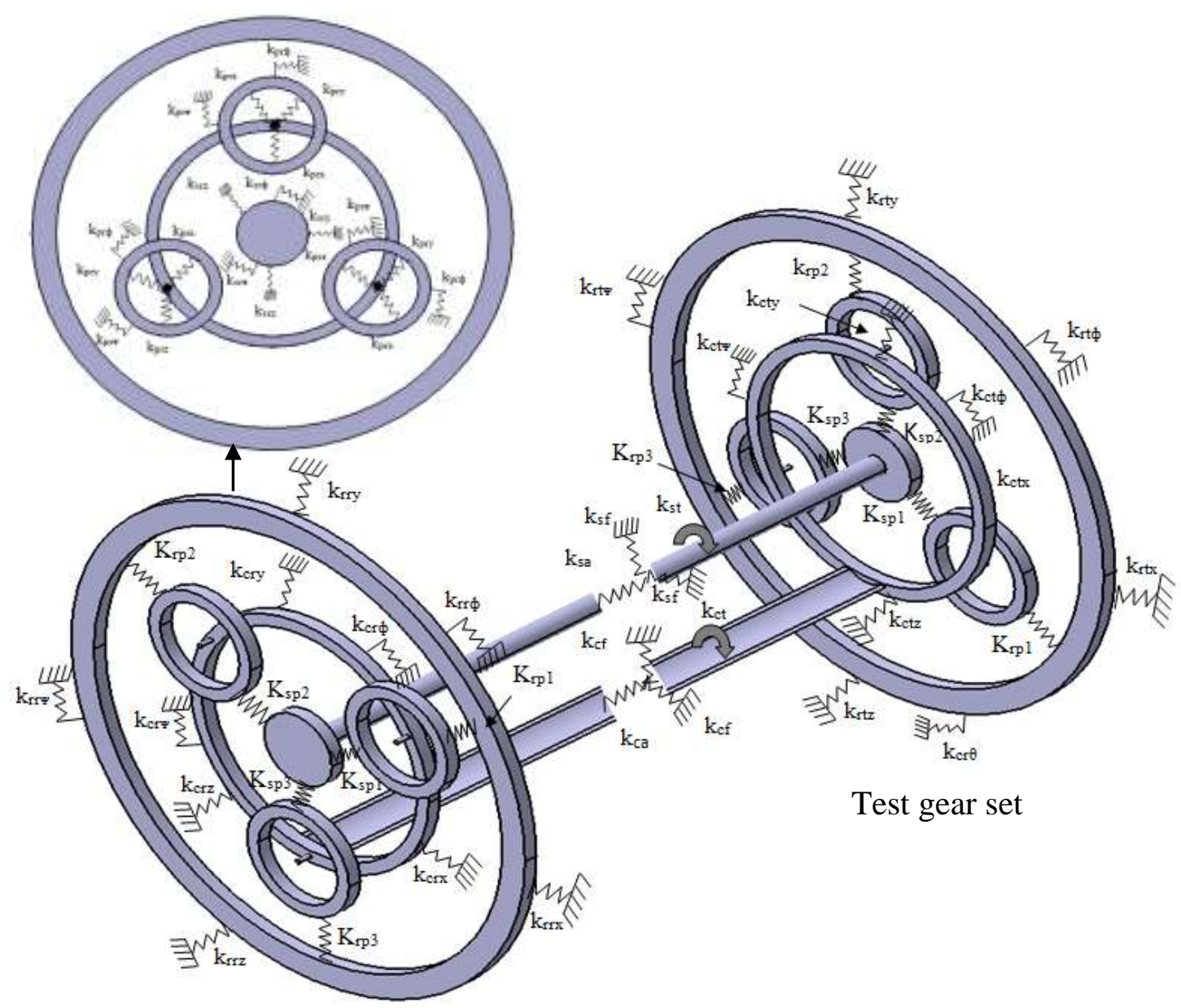

Reaction gear set

Figure 2: Model of planetary gear transmission

Following the procedure given in [24], it is possible to write the equation of motion as:

$$
M \ddot{q}+C \dot{q}+\left(K_{b}+K_{e}(t)\right) q=F(t)
$$

$\boldsymbol{M}$-denotes the mass matrix, $\boldsymbol{C}$ stands for damping matrix, $\boldsymbol{K}_{\boldsymbol{b}}$-denotes the bearing and shaft stiffness matrix, $\boldsymbol{K}_{e}(\boldsymbol{t})$ is the time varying stiffness matrix and $\boldsymbol{F}(\boldsymbol{t})$ stands for the external force vector applied to the system. All these matrices are defined in appendix. The planets sets for the test and reaction planetary gears are identical and equally spaced.

Table 1 shows parameters of the studied planetary gear test bench. 
Table1: Planetary gear and shafts parameters.

\begin{tabular}{|c|c|c|c|c|}
\hline & Sun & Planet & Ring & Carrier \\
\hline \multicolumn{5}{|c|}{ Reaction planetary gear set } \\
\hline Teeth number & 16 & 24 & 65 & - \\
\hline Mass $[\mathrm{Kg}]$ & 0.485 & 1.225 & 28.1 & 3.643 \\
\hline Base diameter $[\mathrm{mm}]$ & 61.38 & 92.08 & 92.08249 .38 & 57.55 \\
\hline $\begin{array}{l}\text { Moment of inertia } \\
{\left[\mathrm{Kgm}^{2}\right]}\end{array}$ & $356 \cdot 10^{-6}$ & $2045 \cdot 10^{-6}$ & $697767 \cdot 10^{-6}$ & $21502 \cdot 10^{-6}$ \\
\hline $\begin{array}{c}\text { Bearing stiffness } \\
{[\mathrm{N} / \mathrm{m}]}\end{array}$ & $\begin{array}{c}\mathrm{k}_{\mathrm{srx}}=\mathrm{k}_{\mathrm{srz}}=1.5 .10^{8} \\
\mathrm{k}_{\mathrm{srz}}=3.10^{8}\end{array}$ & $\begin{array}{c}\mathrm{k}_{\mathrm{prx}}=\mathrm{k}_{\mathrm{pry}}=1.1 .10^{8} \\
\mathrm{k}_{\mathrm{prz}}=3.10^{8}\end{array}$ & $\begin{array}{c}\mathrm{k}_{\mathrm{rrx}}=\mathrm{k}_{\mathrm{rry}}=8.10^{8} \\
\mathrm{k}_{\mathrm{rrz}}=10.10^{8}\end{array}$ & $\begin{array}{c}\mathrm{k}_{\mathrm{crx}}=\mathrm{k}_{\mathrm{crz}}=1.10^{8} \\
\mathrm{k}_{\mathrm{crz}}=5.10^{8}\end{array}$ \\
\hline $\begin{array}{c}\text { Torsional stiffness } \\
{[\mathrm{N} / \mathrm{m}]}\end{array}$ & $\mathrm{k}_{\mathrm{sr} \phi}=\mathrm{k}_{\mathrm{sr} \psi}=6.10^{9}$ & $\mathrm{k}_{\mathrm{pr} \phi}=\mathrm{k}_{\mathrm{pr} \psi}=6.10^{9}$ & $\mathrm{k}_{\mathrm{rr} \phi}=\mathrm{k}_{\mathrm{rr} \psi}=1.5 .10^{9}$ & $\mathrm{k}_{\mathrm{cr} \phi}=\mathrm{k}_{\mathrm{cr} \psi}=610^{9}$ \\
\hline \multicolumn{5}{|c|}{ Test planetary gear set } \\
\hline Teeth number & 16 & 24 & 65 & - \\
\hline Mass $[\mathrm{Kg}]$ & 0.485 & 1.225 & 28.1 & 3.643 \\
\hline Base diameter $[\mathrm{mm}]$ & 61.38 & 92.08 & 249.38 & 57.55 \\
\hline $\begin{array}{l}\text { Moment of inertia } \\
{\left[\mathrm{Kgm}^{2}\right]}\end{array}$ & $356 \cdot 10^{-6}$ & $2045 \cdot 10^{-6}$ & $697767 \cdot 10^{-6}$ & $21502 \cdot 10^{-6}$ \\
\hline $\begin{array}{c}\text { Bearing stiffness } \\
{[\mathrm{N} / \mathrm{m}]}\end{array}$ & $\begin{array}{c}\mathrm{k}_{\mathrm{stx}}=\mathrm{k}_{\mathrm{stz}}=1.5 .10^{8} \\
\mathrm{k}_{\mathrm{stz}}=3.10^{8}\end{array}$ & $\begin{array}{c}\mathrm{k}_{\mathrm{ptx}}=\mathrm{k}_{\mathrm{pry}}=1.1 .10^{8} \\
\mathrm{k}_{\mathrm{ptz}}=3.10^{8}\end{array}$ & $\begin{array}{c}\mathrm{k}_{\mathrm{rtx}}=\mathrm{k}_{\mathrm{rty}}=8.10^{8} \\
\mathrm{k}_{\mathrm{rtz}}=10.10^{8}\end{array}$ & $\begin{array}{c}\mathrm{k}_{\mathrm{crx}}=\mathrm{k}_{\mathrm{crz}}=1.10^{8} \\
\mathrm{k}_{\mathrm{ctz}}=5.10^{8}\end{array}$ \\
\hline $\begin{array}{c}\text { Torsional stiffness } \\
{[\mathrm{N} / \mathrm{m}]}\end{array}$ & $\mathrm{k}_{\mathrm{st} \phi}=\mathrm{k}_{\mathrm{st} \psi}=510^{9}$ & $\mathrm{k}_{\mathrm{pt \phi}}=\mathrm{k}_{\mathrm{pt} \psi}=610^{9}$ & $\begin{array}{l}\mathrm{k}_{\mathrm{rt}}=\mathrm{k}_{\mathrm{rr} \psi}=510^{9} \\
\mathrm{k}_{\mathrm{rt} \theta}=7.9 \cdot 10^{6}\end{array}$ & $\mathrm{k}_{\mathrm{ct} \phi}=\mathrm{k}_{\mathrm{ct} t}=510^{9}$ \\
\hline \multicolumn{5}{|c|}{ Shaft stiffness } \\
\hline Torsional & $3.73 \cdot 10^{4}$ & - & - & $8.38 \cdot 10^{5}$ \\
\hline Flexural & $4.9 \cdot 10^{5}$ & - & - & $1.1 \cdot 10^{7}$ \\
\hline tractional & $4.8510^{8}$ & - & - & $1.2510^{9}$ \\
\hline
\end{tabular}

\section{4-Results:}

In this part, numerical and experimental results of modal analysis with change of load on the back-to-back planetary gears are investigated. The effect of mesh stiffness variation on the modal proprieties is presented as well.

\section{4-1-Effect of load on modal proprieties:}

In this section, different loading levels $(200 \mathrm{Nm}, 400 \mathrm{Nm}, 600 \mathrm{Nm}$ and $800 \mathrm{Nm}$ ) are applied on the free ring-and modal parameters are determined.

In order to define the meshing stiffness functions for all sun-planet and ring-planet meshes, finite elements modelling and Hertzian contact theory are used according to the procedure given by Fernandez et al. [25]. Firstly, the tooth geometry is defined using gear parameters and the location of the contact points is computed by considering the analytic formulation of the involute-involute contact. Then, two phenomena are considered: the first one is the nonlinear local deformations near the contact area where an analytical non-linear formulation of Hertzian type for local deflections is used. The second is the tooth body deflections due to linear bending, 
shearing and compression. Two-dimensional finite elements model of teeth in contact is carried out in order to validate this methodology. The evolution of mesh stiffness functions corresponding to sun-planet and ring-planet are shown in [23].

In this section, mesh stiffness values are obtained by computing the average values of ring-planet and sun-planet mesh stiffness functions (table 2).

\section{4-1-1Effect of load on the natural frequencies and vibration modes:}

The natural frequencies and the vibrations modes are determined by solving the eigenvalue problem:

$$
\left(-\omega_{i}^{2} M+K_{m}\right) \phi_{i}=0
$$

Where $\omega_{i}$ are the natural pulsations and $\phi_{i}$ are the vibration modes. For each load level, natural frequencies and vibrations modes are determined and correlated against those obtained from the impact test.

Figure $3 \mathrm{a}$ and $3 \mathrm{~b}$ show respectively the frequency response function obtained by experimental test and numerical model. Among all frequency response functions, the identified natural frequencies have deviation for different load level which is well observed for high frequencies. This phenomenon is induced by the increase of load and then the variation of mesh stiffness mean value (table 2) but also by the variation of the inertia on the free ring caused by the addition of mass.

Table2: Parameters varied with load.

\begin{tabular}{|c|c|c|c|}
\hline \multirow{2}{*}{ Load $[$ N.m] } & Sun- planet mesh stiffness & Ring- planet mesh stiffness & \multirow{2}{*}{$\begin{array}{l}\text { Inertia of reactior } \\
\text { ring }\left[\mathrm{kg} \cdot \mathrm{m}^{2}\right]\end{array}$} \\
\hline & Average mesh stiffness $[\mathrm{N} / \mathrm{m}]$ & -Average mesh stiffness $[\mathrm{N} / \mathrm{m}]$ & \\
\hline 200 & $4.04 \times 10^{8}$ & $5.84 \times 10^{8}$ & 0.7479 \\
\hline 400 & $4.14 \times 10^{8}$ & $6.07 \times 10^{8}$ & 1.0588 \\
\hline 600 & $4.23 \times 10^{8}$ & $6.27 \times 10^{8}$ & 1.3698 \\
\hline 800 & $4.42 \times 10^{8}$ & $6.69 \times 10^{8}$ & 1.6807 \\
\hline
\end{tabular}



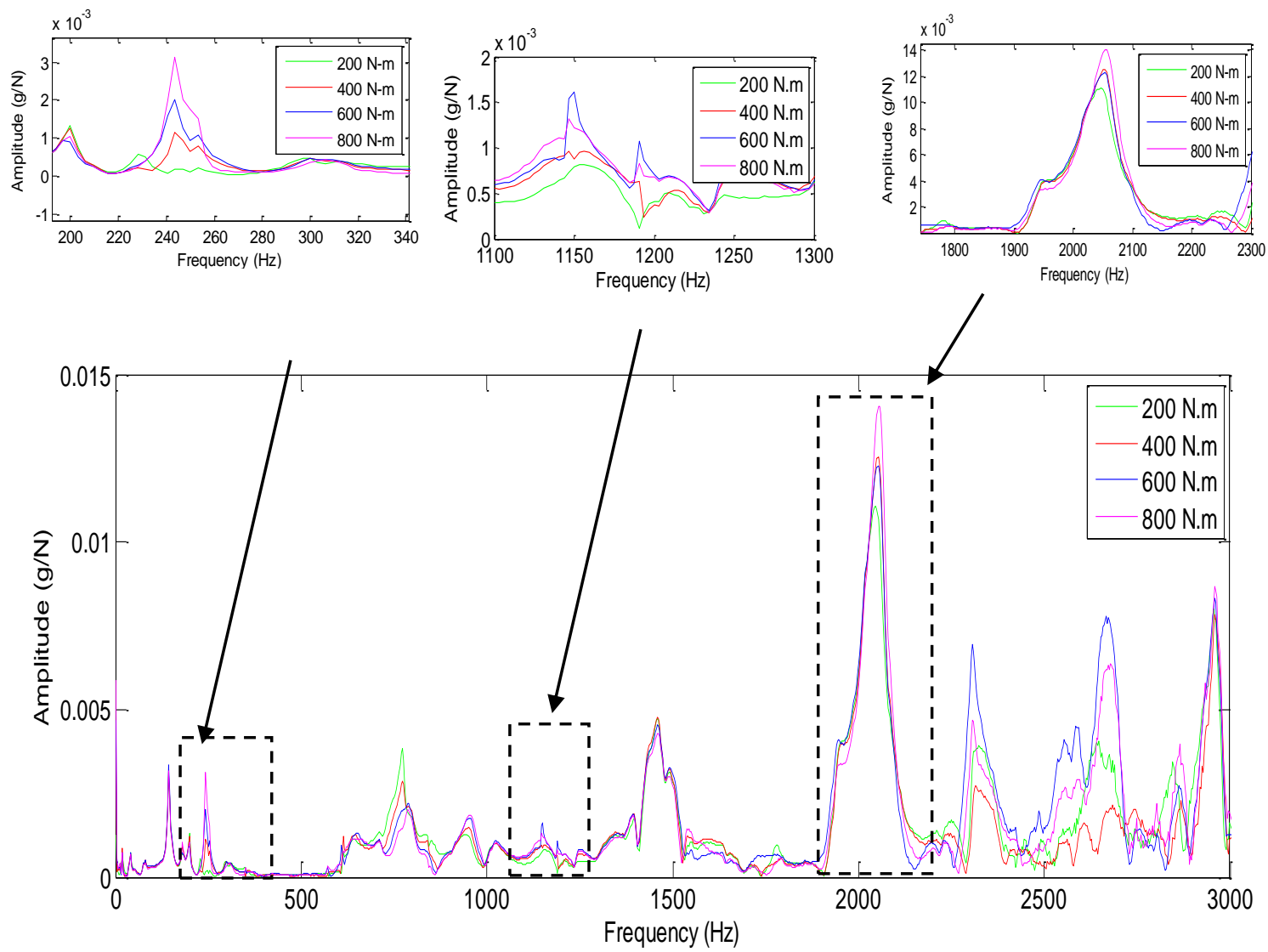

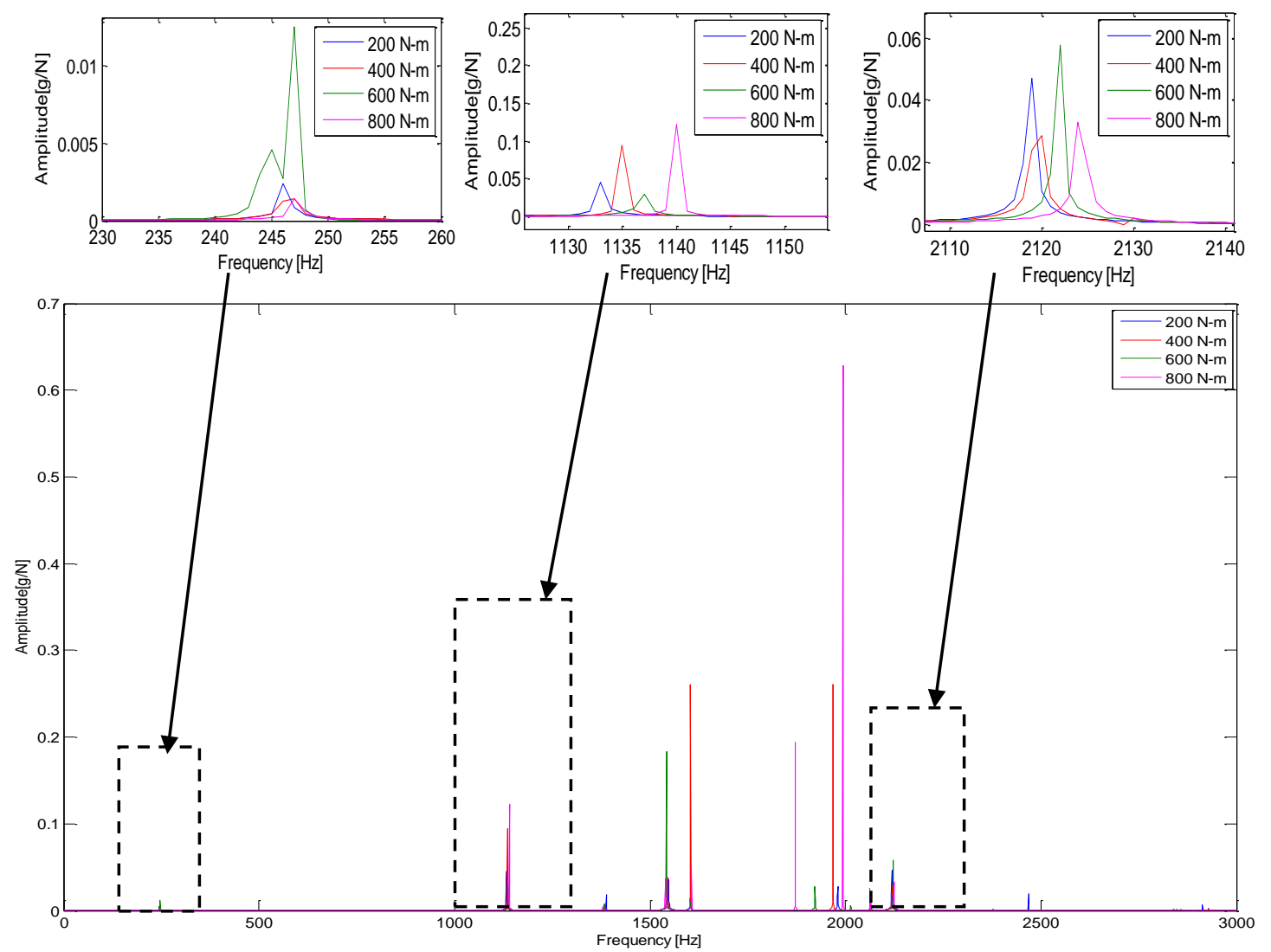

(b)

Figure 3:Frequency Response Function of fix ring (a)exprimental (b)numerical Table 3 shows the influence of load on some selected modes and comparison between numerical and experimental results. Some errors are observed, we think that they are induced by the fact that bearings are considered as isotropic bearings.

Table 3: Numerical-and measured natural frequencies for different applied loads.

\begin{tabular}{|c|c|c|c|c|c|c|c|c|c|c|c|c|c|}
\hline \multirow{2}{*}{ Mode } & \multicolumn{9}{|c|}{ Frequency (Hz) } \\
\cline { 2 - 15 } & \multicolumn{3}{|c|}{$200 \mathrm{Nm}$} & \multicolumn{3}{|c|}{$400 \mathrm{Nm}$} & \multicolumn{3}{|c|}{$600 \mathrm{Nm}$} & \multicolumn{3}{|c|}{$800 \mathrm{Nm}$} \\
\cline { 2 - 15 } & Exp & Num & Error(\%) & Exp & Num & Error(\%) & Exp & Num & Error(\%) & Exp & Num & Error(\%) \\
\hline 8 & 82 & 85 & -3.5 & 82 & 85 & -3.5 & 82 & 85 & -3.5 & 82 & 85 & -3.5 \\
\hline 12 & 140 & 144 & 2.8 & 140 & 144 & 2.8 & 140 & 144 & 2.8 & 140 & 144 & 2.8 \\
\hline 24 & 244 & 238 & 3 & 244 & 238 & 3 & 244 & 238 & 3 & 244 & 239 & 3 \\
\hline 40 & 396 & 392 & 1 & 397 & 393 & 1 & 399 & 395 & 1 & 405 & 399 & 1,4 \\
\hline 53 & 765 & 756 & 1.5 & 769 & 757 & 1.5 & 769 & 765 & 0.5 & 770 & 782 & -1.5 \\
\hline 54 & 1191 & 1133 & 5 & 1191 & 1135 & 5 & 1191 & 1137 & 5 & 1194 & 1340 & 5 \\
\hline 55 & 1244 & 1255 & -1 & 1245 & 1255 & -1 & 1244 & 1255 & -1 & 1246 & 1255 & -1 \\
\hline 57 & 1778 & 1748 & 2.5 & 1779 & 1769 & 1 & 1780 & 1786 & -0.5 & 1780 & 1822 & -2 \\
\hline 59 & 2025 & 2044 & -1 & 2053 & 2055 & -0.5 & 2054 & 2082 & -1 & 2056 & 2132 & -3 \\
\hline 60 & 2303 & 2371 & -3 & 2306 & 2379 & -3 & 2306 & 2382 & -3 & 2306 & 2389 & -3 \\
\hline 61 & 2869 & 2842 & 1 & 2875 & 2849 & 1 & 2900 & 2861 & 1.5 & 2903 & 2890 & -0.5 \\
\hline
\end{tabular}

4-1-2 Analysis of the distribution of modal kinetic and modal strain energies: 
Distribution of modal strain energy and kinetic energy of each component are computed according to Hammami et al. [7]. Two load levels are considered: 200 and $800 \mathrm{Nm}$ and their corresponding strain and kinetic energies distributions are compared. We will be interested to three natural modes $85 \mathrm{~Hz}, 396 \mathrm{~Hz}$ and $2025 \mathrm{~Hz}$ because the number of roller in contact changes from a mode to another mode.

Figure 4 and figure 5 show respectively the distributions of strain energies and kinetic energies for the two-loading condition. It's well observed their sensitivity to load variation.

For 200 N.m load, the dominant strain energy is located in sun-planet and ring-planet meshing of the planetary reaction gear at the natural frequency $85 \mathrm{~Hz}$.For396 Hz and $2025 \mathrm{~Hz}$ modes, the dominant strain energy is located in suns and planets bearings of the planetary reaction gear.

For 800 N.m load, the dominant strain energy is located in sun and planet bearings of the planetary reaction gear at $85 \mathrm{~Hz}$.For $396 \mathrm{~Hz}$ and $2025 \mathrm{~Hz}$, the dominant strain energy is located in suns and planets bearings of the planetary test gear.

We notice that with increasing of load, the location of dominant strain energy changes from teeth meshing to bearings as well as from the reaction gear component to the test gear component. This change is due to the variation of modal deflection as well as the variation of contact between teeth. However, Kinetic energy distribution changes slightly. 


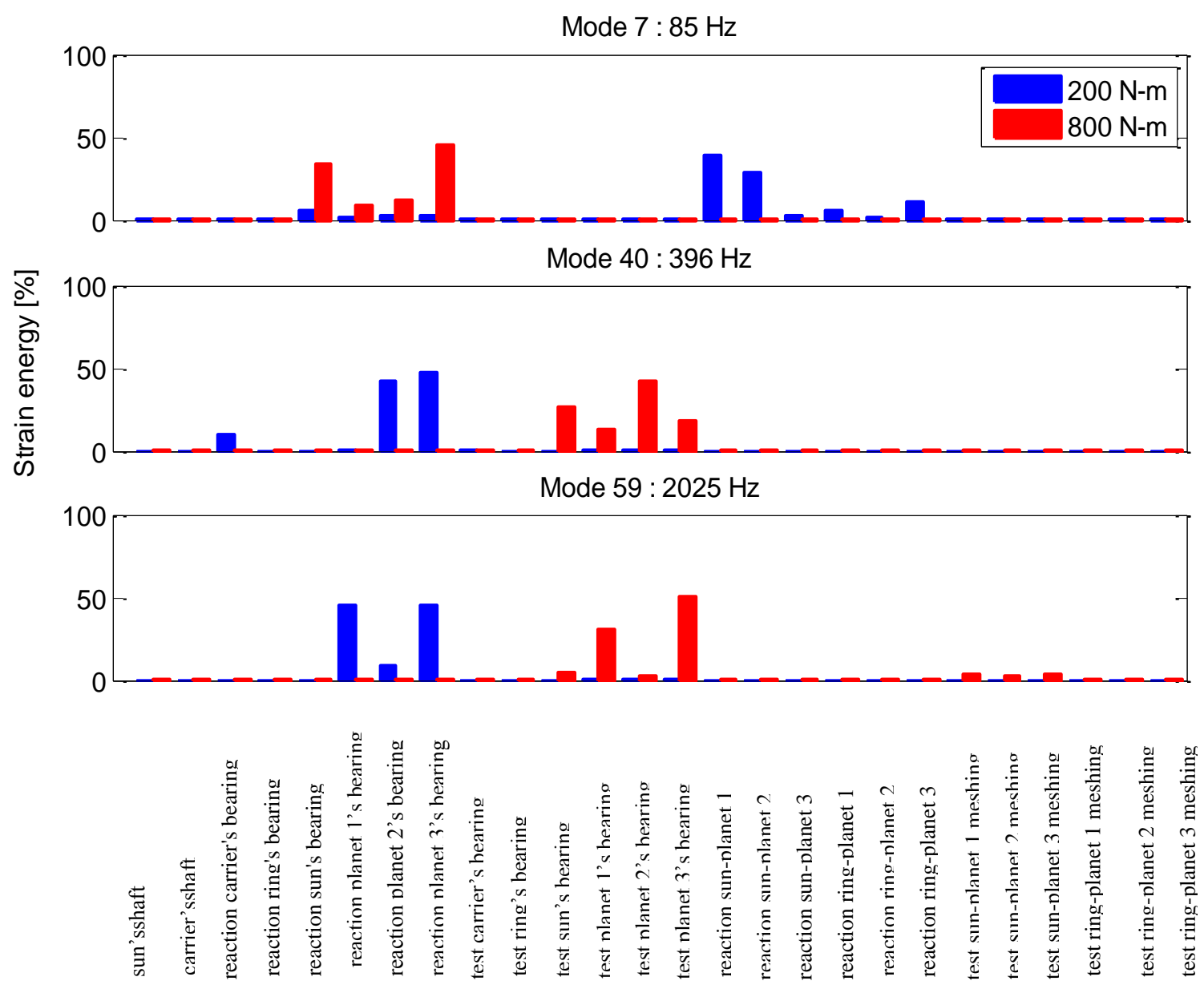

Figure 4: Modal strain energy distribution

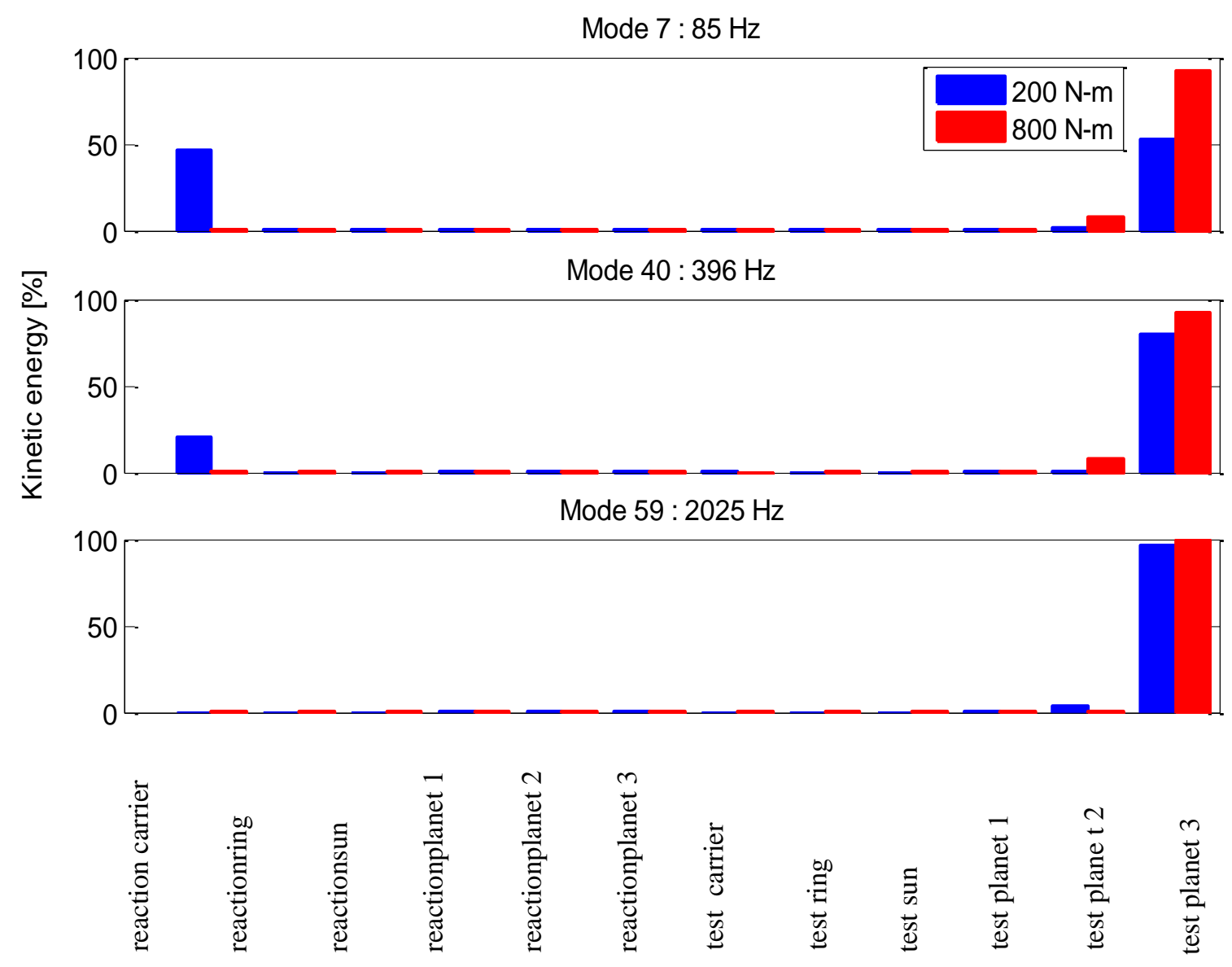


Figure 5: Modal kinetic energy distribution

\subsection{Effect of variation of meshing stiffness:}

The objective of this part is to study the effect of variation of mesh stiffness during one meshing period on modal properties of the planetary gear.

Planets are equally spaced and the contact sun-planets and ring planets are sequentially phased. Mesh stiffness is modelled for one period according to the procedure described in section 4.1.

Figure 6.a and figure 6.b show respectively the modelling of sun planet and ring planet mesh stiffness functions.

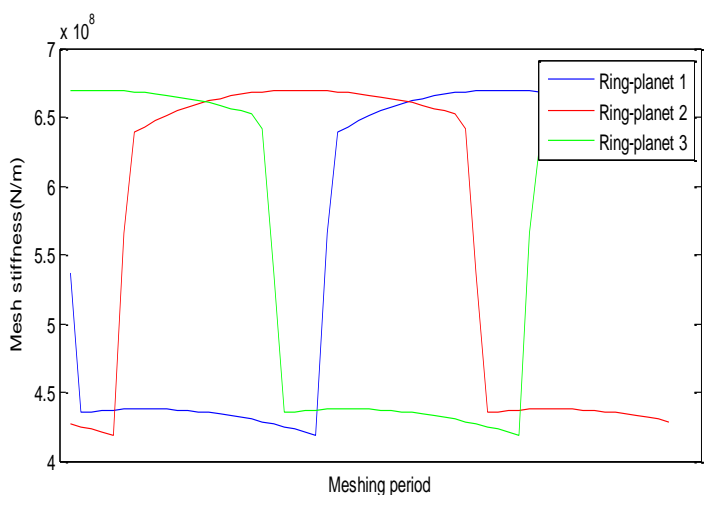

(a)

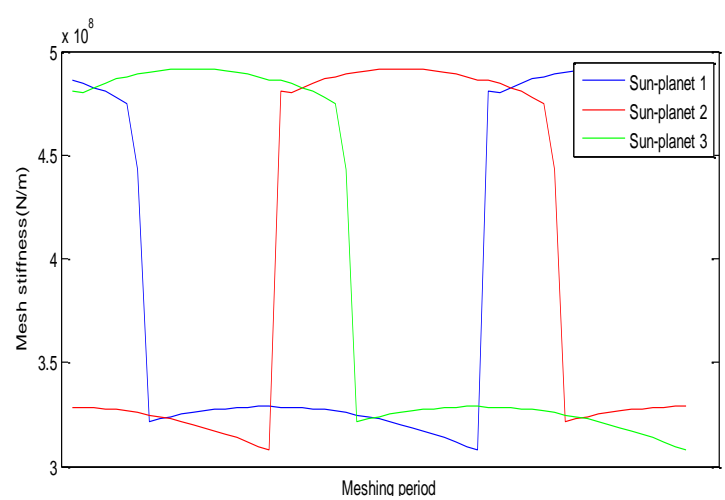

(b)

Figure 6: Mesh stiffness function (a) Sun-planet (b) Ring-planet

Frequency response functions are computed for each instantaneous value of mesh stiffness during one meshing period. Figures $7 \mathrm{a}$ and $7 \mathrm{~b}$, show respectively the numerical and experimental evolution of the frequency response function with respect to the mesh stiffness values in one meshing period. The impact tests are carried out step by step: a meshing period is selected and subdivided into different graduations. For each graduation, the impact test is achieved and the frequency response functions are recorded on the test ring. For both numerical and experimental results, the variation of mesh stiffness introduced slight deviation of natural frequencies. This deviation is repeated three times in one meshing period. This behaviour is explained by the fact that the contact sun-planets and ring planets are sequentially phased and the number of planets is three- Natural frequencies changes approximately by $2 \%$ in the numerical results and by $3 \%$ in the experimental results.

In addition, the-amplitudes of frequency response functions change during the meshing period which is caused by the variation of contact points location between mating teeth and the variation of meshing stiffness values. 

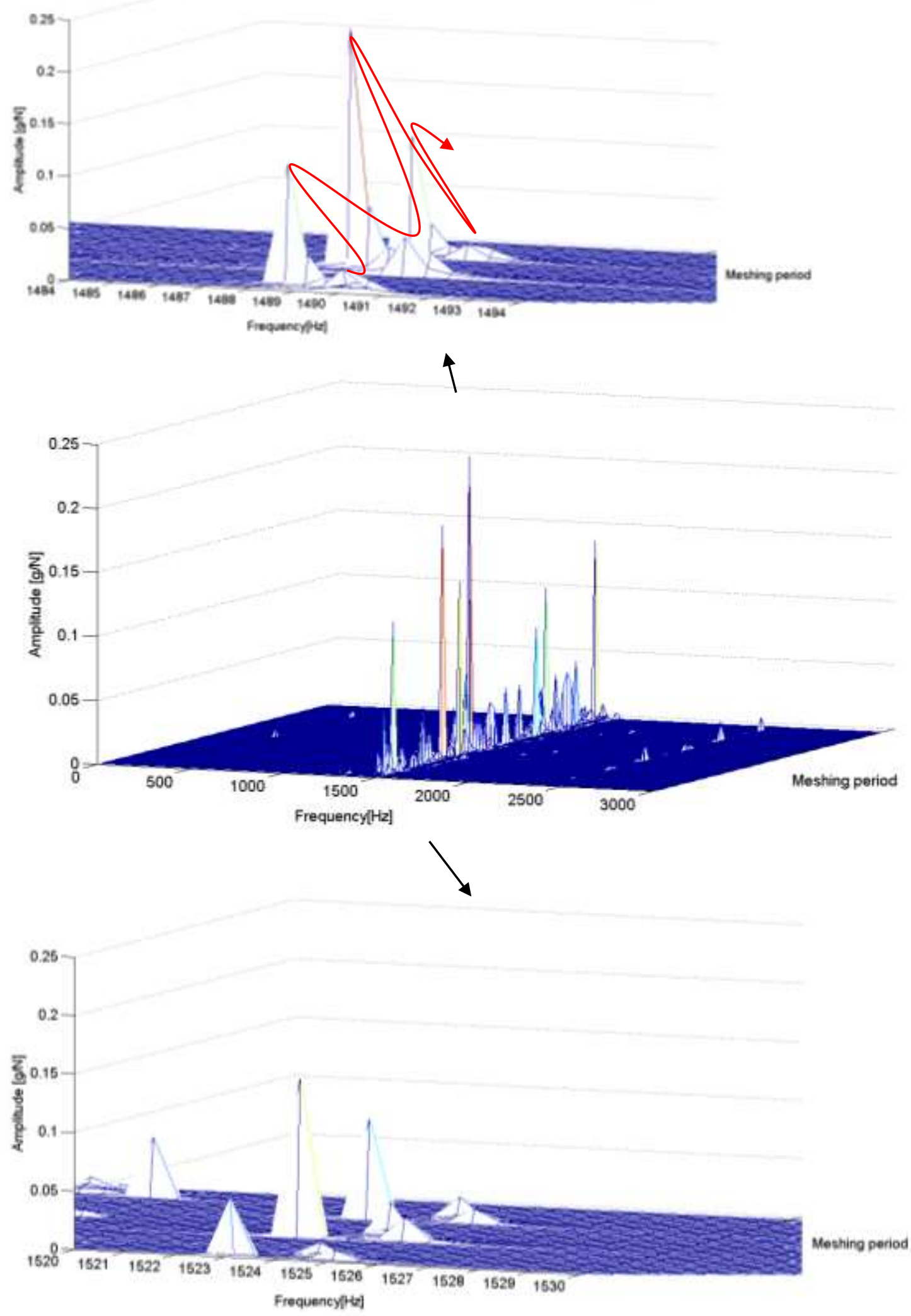

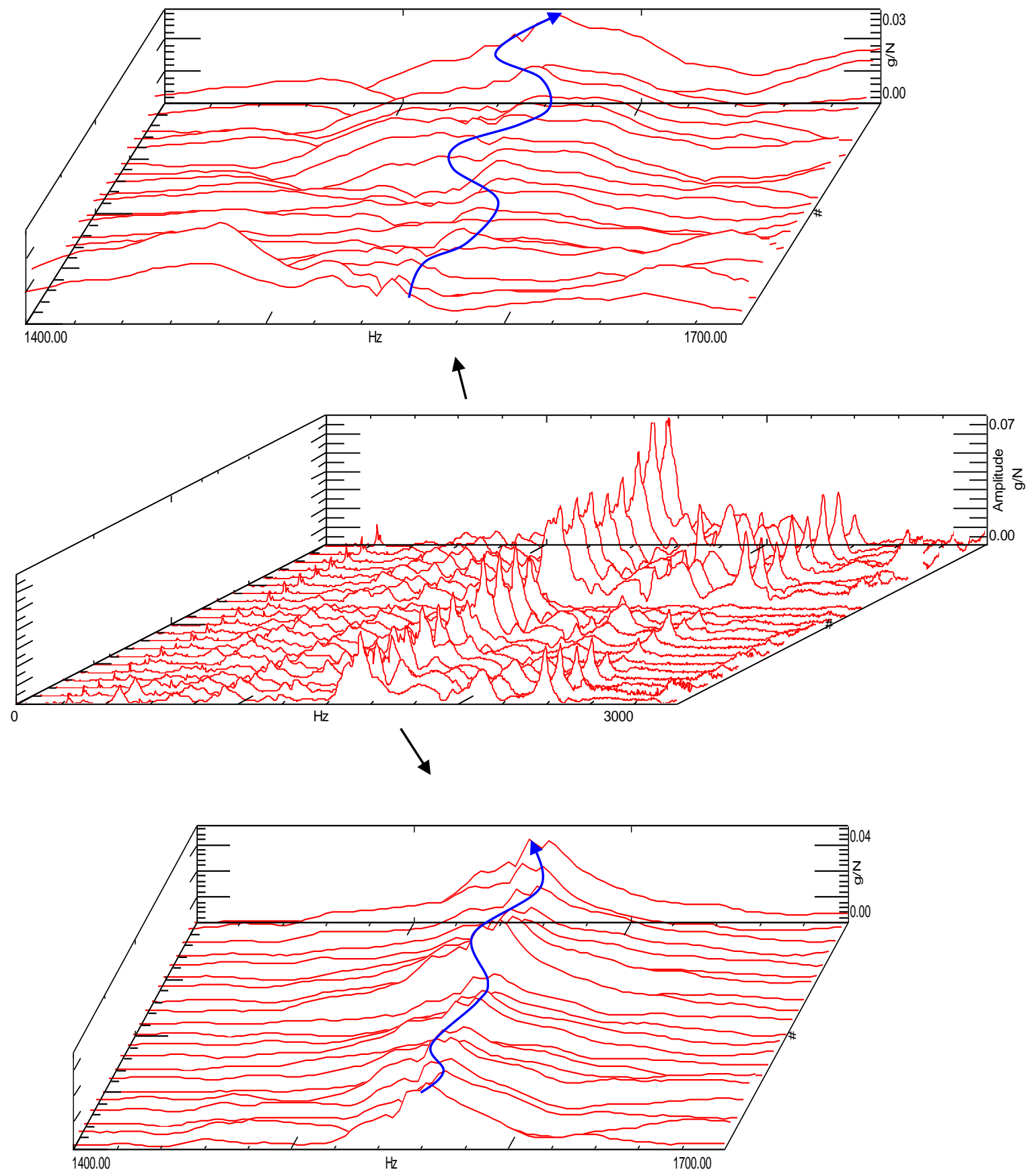

(b)

Figure 7: Waterfall plot of Frequency Response Function on the test ring(a)numerical(b)experimental 


\section{Conclusion}

Modal analysis with change of load and meshing stiffness variation-was investigated by means of experimental impact tests and lumped parameter model of gear set. In first step, three-dimensional planetary gear model has been developed. Furthermore, the effect load on modal proprieties was studied experimentally and numerically with four load levels. For each level, frequency response functions were measured on the test ring and then the natural frequencies are identified. The sensitivity of natural frequencies to the load is well noticed. With the increasing of load, natural frequencies increase. Moreover, the analysis of the distributions of modal kinetic energies and modal strain energies for two load level showed that the increase of load results in a change of the location of strain energy from teeth to bearing as well as from reaction gear component to test gear component. This change is due to the variation of modal deflection in each component.

For mesh stiffness variation, a parametric test was carried out using the test bench. A meshing period was selected and subdivided into different graduations. For each graduation, the frequency response functions were recorded on the test ring and presented in waterfall plot. The measured results were correlated with those obtained by numerical model highlighting the fact that natural frequencies vary with mesh position.

A slight deviation of about 2-3\% repeated three times on the waterfall plot of the frequency response functions in one meshing period were showed in both numerical and experimental results. These deviations are explained by the fact that planets are considered equally spaced and sequentially phased during one meshing period. In upcoming work, we will study the effect of load and variation of meshing stiffness, including the gyroscopic effects and using the Operational Modal Analysis techniques.

\section{Acknowledgements}

This paper was financially supported by the Tunisian-Spanish Joint Project No. A1/037038/11.The authors would like also to acknowledge project "Development of methodologies for the simulationand improvement of the dynamic behavior of planetary transmissions DPI2013-44860" funded by theSpanish Ministry of Science and Technology.

Acknowledgment to the University of Cantabria cooperation project for doctoral training of Universityof Sfax's students. 


\section{Appendix}

$\mathrm{q}_{\mathrm{r}}$ is the degree of freedom vector of the reaction gear set ( $\mathrm{r}$ ) and $\mathrm{q}_{\mathrm{t}}$ is the degree of freedom vector of the test gear set $(\mathrm{t})$.

$\mathrm{q}=\left\{\begin{array}{l}q_{r} \\ q_{t}\end{array}\right\}$

$q_{t}=\left\{U_{c t}, V_{c t}, W_{c t}, \rho_{c x t}, \rho_{c y t}, \rho_{c z t}, U_{r t}, V_{r t}, W_{r t}, \rho_{r x t}, \rho_{r y t}, \rho_{r z t}, U_{s t}, V_{s t}, W_{s t}, \rho_{s x t}, \rho_{s y t}, \rho_{s z t}\right.$,

$\left.U_{1 t}, V_{1 t}, W_{1 t}, \rho_{1 x t}, \rho_{1 y t}, \rho_{3 z t}, U_{2 t}, V_{2 t}, W_{2 r t}, \rho_{2 x t}, \rho_{2 y t}, \rho_{2 z t}, U_{3 t}, V_{3 t}, W_{3 t}, \rho_{3 x t}, \rho_{3 y t}, \rho_{3 z t}\right\}$

$q_{r}=\left\{U_{c r}, V_{c r}, W_{c r}, \rho_{c x r}, \rho_{c y r}, \rho_{c z r}, U_{r r}, V_{r r}, W_{r r}, \rho_{r x r}, \rho_{r y r}, \rho_{r z r}, U_{s r}, V_{s r}, W_{s r}, \rho_{s x r}, \rho_{s y r}, \rho_{s z r}\right.$,

$\left.U_{1 r}, V_{1 r}, W_{1 r}, \rho_{1 x r}, \rho_{1 y r}, \rho_{1 z r}, U_{2 r}, V_{2 r}, W_{2 r}, \rho_{2 x r}, \rho_{2 y r}, \rho_{2 z r}, U_{3 r}, V_{3 r}, W_{3 r}, \rho_{3 x r}, \rho_{3 y r}, \rho_{3 z r}\right\}$

M: global mass matrix

$\mathrm{K}_{\mathrm{b}}$ : bearing stiffness matrix

$\mathrm{Ke}(\mathrm{t})$ : time varying mesh stiffness matrix

$\mathrm{M}=\left[\begin{array}{cc}M_{t} & 0 \\ 0 & M_{r}\end{array}\right]$

$\mathrm{M}_{\mathrm{i}}=\left[\begin{array}{cccccc}M_{c} & 0 & 0 & 0 & 0 & 0 \\ 0 & M_{r} & 0 & 0 & 0 & 0 \\ 0 & 0 & M_{s} & 0 & 0 & 0 \\ 0 & 0 & 0 & M_{1} & 0 & 0 \\ 0 & 0 & 0 & 0 & M_{2} & 0 \\ 0 & 0 & 0 & 0 & 0 & M_{3}\end{array}\right] \mathrm{i}=\mathrm{t}, \mathrm{r}$

with $M_{j}=\left[\begin{array}{cccccc}m_{j} & 0 & 0 & 0 & 0 & 0 \\ 0 & m_{j} & 0 & 0 & 0 & 0 \\ 0 & 0 & m_{j} & 0 & 0 & 0 \\ 0 & 0 & 0 & \frac{I_{j}}{r^{2}{ }_{j}} & 0 & 0 \\ 0 & 0 & 0 & 0 & \frac{I_{j}}{r^{2}{ }_{j}} & 0 \\ 0 & 0 & 0 & 0 & 0 & \frac{2 * I_{j}}{r^{2}}\end{array}\right] \mathrm{j}=\mathrm{c}, \mathrm{r}, \mathrm{s}, 1,2,3$

$I_{j}$ is the inertial moment of the $j^{\text {th }}$ element with respect to its rotational axis.

The bearing stiffness matrix $K_{b}$ 
$K_{b}=\operatorname{diag}\left(K_{c r}, K_{r r}, K_{s r}, K_{1 r}, K_{2 r}, K_{3 r}, K_{c t}, K_{r t}, K_{s t}, K_{1 t}, K_{2 t}, K_{3 t}\right)$

$K_{i j}=\operatorname{diag}\left(K_{i j x}, K_{i j y}, K_{i j z}, K_{i j^{s}}, K_{i j}, K_{i j}\right) \mathrm{i}=\mathrm{c}, \mathrm{r}, \mathrm{s}$,

$K_{k j b}=\operatorname{diag}\left(K_{k j b}, K_{k j b}, K_{k j b}, K_{k^{s}}, K_{k j^{\natural},}, 0\right) k=1,2,3 \mathrm{j}=\mathrm{r}$,

$\psi_{r}=\alpha_{i}+\alpha_{r}$

$\psi_{s}=\alpha_{i}-\alpha_{s}$

The stiffness matrix $K_{m}$ :

$K_{m}=\left[\begin{array}{cc}K_{m r} & 0 \\ 0 & K_{m t}\end{array}\right]+K_{c}$

$K_{m}=\left[\begin{array}{cccccc}\sum K_{c 1}^{n} & 0 & 0 & K_{c 2}^{1} & K_{c 2}^{2} & K_{c 2}^{3} \\ 0 & \sum K_{r 1}^{n} & 0 & K_{r 2}^{1} & K_{r 2}^{2} & K_{r 2}^{2} \\ 0 & 0 & \sum K_{s 1}^{n} & K_{s 2}^{1} & K_{s 2}^{2} & K_{s 2}^{3} \\ K_{c 2}^{1} & K_{r 2}^{1} & K_{s 2}^{1} & K_{P P}^{1} & 0 & 0 \\ K_{c 2}^{2} & K_{r 2}^{2} & K_{s 2}^{2} & 0 & K_{P P}^{2} & 0 \\ K_{c 2}^{3} & K_{r 2}^{3} & K_{s 2}^{3} & 0 & 0 & K_{P P}^{3}\end{array}\right]$

$K_{p p}^{n}=K_{c 3}^{n}+K_{r 3}^{n}+K_{s 3}^{3}$

$K_{c l}^{n}=\left[\begin{array}{c}\cos ^{2}\left(\alpha_{\mathrm{i}}\right) K_{X X}+\sin ^{2}\left(\alpha_{\mathrm{i}}\right) K_{Y Y} \\ \cos \left(\alpha_{\mathrm{i}}\right) \sin \left(\alpha_{\mathrm{i}}\right) K_{X X}-\sin \left(\alpha_{\mathrm{i}}\right) \cos \left(\alpha_{\mathrm{i}}\right) K_{Y Y} \\ 0 \\ 0 \\ 0 \\ -\sin \left(\alpha_{\mathrm{i}}\right) K_{Y Y}\end{array}\right.$ $\cos \left(\alpha_{\mathrm{i}}\right) \sin \left(\alpha_{\mathrm{i}}\right) K_{X X}-\sin \left(\alpha_{\mathrm{i}}\right) \cos \left(\alpha_{\mathrm{i}}\right) K_{Y Y}$ $\sin ^{2}\left(\alpha_{\mathrm{ii}}\right) K_{X X}+\cos ^{2}\left(\alpha_{\mathrm{i}}\right) K_{Y Y}$

\section{0}

0

0

$\cos \left(\alpha_{\mathrm{i}}\right) K_{Y Y}$

$\left.\begin{array}{cccc}0 & 0 & 0 & -\sin \left(\alpha_{\mathrm{i}}\right) K_{Y Y} \\ 0 & 0 & 0 & \cos \left(\alpha_{\mathrm{i}}\right) K_{Y Y} \\ K_{z z} & \sin \left(\alpha_{\mathrm{i}}\right) K_{z z} & -\cos \left(\alpha_{\mathrm{i}}\right) K_{z z} & 0 \\ \sin \left(\alpha_{\mathrm{i}}\right) K_{z z} & \sin ^{2}\left(\alpha_{\mathrm{i}}\right) K_{z z} & -\sin \left(\alpha_{\mathrm{i}}\right) \cos \left(\alpha_{\mathrm{i}}\right) K_{z z} & 0 \\ -\cos \left(\alpha_{\mathrm{i}}\right) K_{z z} & -\sin \left(\alpha_{\mathrm{i}}\right) \cos \left(\alpha_{\mathrm{ii}}\right) K_{z z} & \cos ^{2}\left(\alpha_{\mathrm{i}}\right) K_{z z} & 0 \\ 0 & 0 & 0 & K_{z z}\end{array}\right]$

$K_{r 1}^{n}=K_{r p}\left[\begin{array}{cccccc}\sin ^{2}\left(\psi_{r}\right) & -\varepsilon \sin \left(\psi_{r}\right) \cos \left(\psi_{r}\right) & 0 & \frac{\varepsilon}{R b_{r}} \sin \left(\psi_{r}\right) \cos \left(\psi_{r}\right) & -\frac{1}{R b_{r}} \sin ^{2}\left(\psi_{r}\right) & -\varepsilon \sin \left(\psi_{r}\right) \\ -\varepsilon \sin \left(\psi_{r}\right) \cos \left(\psi_{r}\right) & \cos ^{2}\left(\psi_{r}\right) & 0 & -\frac{\varepsilon^{2}}{R b_{r}} \cos ^{2}\left(\psi_{r}\right) & \frac{1}{R b_{r}} \sin \left(\psi_{r}\right) \cos \left(\psi_{r}\right) & \varepsilon^{2} \cos \left(\psi_{r}\right) \\ 0 & 0 & 0 & 0 & 0 & 0 \\ \frac{\varepsilon}{R b_{r}} \sin \left(\psi_{r}\right) \cos \left(\psi_{r}\right) & -\frac{\varepsilon^{2}}{R b_{r}} \cos ^{2}\left(\psi_{r}\right) & 0 & \frac{\varepsilon^{2}}{\left(R b_{r}\right)^{2}} \cos ^{2}\left(\psi_{r}\right) & -\frac{\varepsilon}{\left(R b_{r}\right)^{2}} \sin \left(\psi_{r}\right) \cos \left(\psi_{r}\right) & -\frac{\varepsilon^{2}}{R b_{r}} \cos \left(\psi_{r}\right) \\ -\frac{1}{R b_{r}} \sin ^{2}\left(\psi_{r}\right) & \frac{\varepsilon}{R b_{r}} \sin \left(\psi_{r}\right) \cos \left(\psi_{r}\right) & 0 & -\frac{\varepsilon}{\left(R b_{r}\right)^{2}} \sin \left(\psi_{r}\right) \cos \left(\psi_{r}\right) & \frac{1}{\left(R b_{r}\right)^{2}} \sin ^{2}\left(\psi_{r}\right) & \frac{\varepsilon}{R b_{r}} \sin \left(\psi_{r}\right) \\ -\varepsilon \sin \left(\psi_{r}\right) & \varepsilon^{2} \cos \left(\psi_{r}\right) & 0 & -\frac{\varepsilon^{2}}{R b_{r}} \cos \left(\psi_{r}\right) & \frac{\varepsilon}{R b_{r}} \sin \left(\psi_{r}\right) & \varepsilon^{2}\end{array}\right]$ 
$K_{s 1}^{n}=K_{s p}\left[\begin{array}{cccccc}\sin ^{2}\left(\psi_{s}\right) & \varepsilon \sin \left(\psi_{s}\right) \cos \left(\psi_{s}\right) & 0 & -\frac{\varepsilon}{R b_{s}} \sin \left(\psi_{s}\right) \cos \left(\psi_{s}\right) & \frac{1}{R b_{s}} \sin ^{2}\left(\psi_{s}\right) & \varepsilon \sin \left(\psi_{s}\right) \\ \varepsilon \sin \left(\psi_{s}\right) \cos \left(\psi_{s}\right) & \varepsilon^{2} \cos ^{2}\left(\psi_{s}\right) & 0 & -\frac{\varepsilon^{2}}{R b_{s}} \cos ^{2}\left(\psi_{s}\right) & \frac{\varepsilon}{R b_{s}} \sin \left(\psi_{s}\right) \cos \left(\psi_{s}\right) & \varepsilon^{2} \cos \left(\psi_{s}\right) \\ 0 & 0 & 0 & 0 & 0 \\ -\frac{\varepsilon}{R b_{s}} \sin \left(\psi_{s}\right) \cos \left(\psi_{s}\right) & -\frac{\varepsilon^{2}}{R b_{s}} \cos ^{2}\left(\psi_{s}\right) & 0 & \frac{\varepsilon^{2}}{\left(R b_{s}\right)^{2}} \cos ^{2}\left(\psi_{s}\right) & -\frac{\varepsilon}{\left(R b_{s}\right)^{2}} \sin \left(\psi_{s}\right) \cos \left(\psi_{s}\right) & -\frac{\varepsilon^{2}}{R b_{s}} \cos \left(\psi_{s}\right) \\ \frac{1}{R b_{s}} \sin ^{2}\left(\psi_{s}\right) & \frac{\varepsilon}{R b_{s}} \sin \left(\psi_{s}\right) \cos \left(\psi_{s}\right) & 0 & -\frac{\varepsilon}{\left(R b_{s}\right)^{2}} \sin \left(\psi_{s}\right) \cos \left(\psi_{s}\right) & \frac{1}{\left(R b_{s}\right)^{2}} \sin ^{2}\left(\psi_{s}\right) & \frac{\varepsilon}{R b_{s}} \sin \left(\psi_{s}\right) \\ \varepsilon \sin \left(\psi_{s}\right) & \varepsilon^{2} \cos \left(\psi_{s}\right) & 0 & -\frac{\varepsilon^{2}}{R b_{s}} \cos \left(\psi_{s}\right) & \frac{\varepsilon}{R b_{s}} \sin \left(\psi_{s}\right) & 1\end{array}\right]$

$$
K_{c 2}^{n}=\left[\begin{array}{cccccc}
-\cos \left(\alpha_{\mathrm{i}}\right) \mathrm{K}_{\mathrm{XX}} & \sin \left(\alpha_{\mathrm{i}}\right) \mathrm{K}_{\mathrm{YY}} & \mathrm{O} & \mathrm{O} & \mathrm{O} & \mathrm{O} \\
-\sin \left(\alpha_{\mathrm{i}}\right) \mathrm{K}_{\mathrm{XX}} & -\cos \left(\alpha_{\mathrm{i}}\right) \mathrm{K}_{\mathrm{YY}} & \mathrm{O} & \mathrm{O} & \mathrm{O} & \mathrm{O} \\
\mathrm{O} & \mathrm{O} & -\mathrm{K}_{\mathrm{ZZ}} & \mathrm{O} & \mathrm{O} & \mathrm{O} \\
\mathrm{O} & \mathrm{O} & -\sin \left(\alpha_{\mathrm{i}}\right) \mathrm{K}_{\mathrm{ZZ}} & \mathrm{O} & \mathrm{O} & \mathrm{O} \\
\mathrm{O} & \mathrm{O} & \cos \left(\alpha_{\mathrm{i}}\right) \mathrm{K}_{\mathrm{ZZ}} & \mathrm{O} & \mathrm{O} & \mathrm{O} \\
\mathrm{O} & -\mathrm{K}_{\mathrm{YY}} & \mathrm{O} & \mathrm{O} & \mathrm{O} & \mathrm{O}
\end{array}\right]
$$

$K_{r 2}^{n}=K_{r p}\left[\begin{array}{cclccc}-\sin \left(\psi_{r}\right) \sin \left(\alpha_{c}\right) & \varepsilon \sin \left(\psi_{r}\right) \cos \left(\alpha_{c}\right) & 0 & \frac{\varepsilon}{R b_{p}} \sin \left(\psi_{r}\right) \cos \left(\alpha_{c}\right) & -\frac{1}{R b_{p}} \sin \left(\psi_{r}\right) \sin \left(\alpha_{c}\right) & \varepsilon \sin \left(\psi_{r}\right) \\ \varepsilon \cos \left(\psi_{r}\right) \sin \left(\alpha_{c}\right) & -\varepsilon^{2} \cos \left(\psi_{r}\right) \cos \left(\alpha_{c}\right) & 0 & -\frac{\varepsilon^{2}}{R b_{p}} \cos \left(\psi_{r}\right) \cos \left(\alpha_{c}\right) & \frac{\varepsilon}{R b_{p}} \cos \left(\psi_{r}\right) \sin \left(\alpha_{c}\right) & -\varepsilon^{2} \cos \left(\psi_{r}\right) \\ 0 & 0 & 0 & 0 & 0 \\ -\frac{\varepsilon}{R b_{r}} \cos \left(\psi_{r}\right) \sin \left(\alpha_{c}\right) & \frac{\varepsilon^{2}}{R b_{r}} \cos \left(\psi_{r}\right) \cos \left(\alpha_{c}\right) & 0 & \frac{1}{R b_{r}} \frac{\varepsilon^{2}}{R b_{p}} \cos \left(\psi_{r}\right) \cos \left(\alpha_{c}\right) & -\frac{1}{R b_{r}} \frac{\varepsilon}{R b_{p}} \cos \left(\psi_{r}\right) \sin \left(\alpha_{c}\right) & \frac{\varepsilon^{2}}{R b_{r}} \cos \left(\psi_{r}\right) \\ \frac{1}{R b_{r}} \sin \left(\psi_{r}\right) \sin \left(\alpha_{c}\right) & -\frac{\varepsilon}{R b_{r}} \sin \left(\psi_{r}\right) \cos \left(\alpha_{c}\right) & 0 & -\frac{1}{R b_{r}} \frac{\varepsilon}{R b_{p}} \sin \left(\psi_{r}\right) \cos \left(\alpha_{c}\right) & \frac{1}{R b_{r}} \frac{1}{R b_{p}} \sin \left(\psi_{r}\right) \sin \left(\alpha_{c}\right) & \frac{\varepsilon}{R b_{r}} \sin \left(\psi_{r}\right) \\ \varepsilon \sin \left(\alpha_{c}\right) & -\varepsilon^{2} \cos \left(\alpha_{c}\right) & 0 & -\frac{\varepsilon^{2}}{R b_{p}} \cos \left(\alpha_{c}\right) & \frac{\varepsilon}{R b_{p}} \sin \left(\alpha_{c}\right) & -\varepsilon^{2}\end{array}\right]$

$$
K_{s 2}^{n}=K_{s p}\left[\begin{array}{cclccc}
-\sin \left(\psi_{s}\right) \sin \left(\alpha_{s}\right) & -\varepsilon \sin \left(\psi_{s}\right) \cos \left(\alpha_{s}\right) & 0 & \frac{\varepsilon}{R b_{P}} \cos \left(\alpha_{s}\right) \sin \left(\psi_{s}\right) & -\frac{1}{R b_{P}} \sin \left(\alpha_{s}\right) \sin \left(\psi_{s}\right) & \varepsilon \sin \left(\psi_{s}\right) \\
-\varepsilon \cos \left(\psi_{s}\right) \sin \left(\alpha_{s}\right) & -\varepsilon^{2} \cos \left(\psi_{s}\right) \cos \left(\alpha_{s}\right) & 0 & \frac{\varepsilon^{2}}{R b_{P}} \cos \left(\alpha_{s}\right) \cos \left(\psi_{s}\right) & -\frac{\varepsilon}{R b_{P}} \sin \left(\alpha_{s}\right) \cos \left(\psi_{s}\right) & \varepsilon^{2} \cos \left(\psi_{s}\right) \\
0 & 0 & 0 & 0 & 0 \\
\frac{\varepsilon}{R b_{s}} \cos \left(\psi_{s}\right) \sin \left(\alpha_{s}\right) & \left.\frac{\varepsilon^{2}}{R b_{s}} \cos \left(\psi_{s}\right) \cos \alpha_{s}\right) & 0 & \frac{1}{R b_{s}} \frac{\varepsilon^{2}}{R b_{P}} \cos \left(\alpha_{s}\right) \cos \left(\psi_{s}\right) & -\frac{1}{R b_{s}} \frac{\varepsilon}{R b_{P}} \sin \left(\alpha_{s}\right) \cos \left(\psi_{s}\right) & \frac{\varepsilon^{2}}{R b_{s}} \cos \left(\psi_{s}\right) \\
-\frac{1}{R b_{s}} \sin \left(\psi_{s}\right) \sin \left(\alpha_{s}\right) & -\frac{\varepsilon}{R b_{s}} \sin \left(\psi_{s}\right) \cos \left(\alpha_{s}\right) & 0 & -\frac{1}{R b_{s}} \frac{\varepsilon}{R b_{P}} \cos \left(\alpha_{s}\right) \sin \left(\psi_{s}\right) & \frac{1}{R b_{s}} \frac{1}{R b_{P}} \sin \left(\alpha_{s}\right) \sin \left(\psi_{s}\right) & -\frac{\varepsilon}{R b_{s}} \sin \left(\psi_{s}\right) \\
-\varepsilon \sin \left(\alpha_{s}\right) & -\varepsilon^{2} \cos \left(\alpha_{s}\right) & 0 & \frac{\varepsilon^{2}}{R b_{P}} \cos \left(\alpha_{s}\right) & -\frac{\varepsilon}{R b_{s t}} \sin \left(\alpha_{s}\right) & \varepsilon^{2}
\end{array}\right]
$$




$$
K_{c 3}^{n}=K_{p n}\left[\begin{array}{cccccc}
K_{X X} & 0 & 0 & 0 & 0 & 0 \\
0 & K_{Y Y} & 0 & 0 & 0 & 0 \\
0 & 0 & K_{Z Z} & 0 & 0 & 0 \\
0 & 0 & 0 & 0 & 0 & 0 \\
0 & 0 & 0 & 0 & 0 & 0 \\
0 & 0 & 0 & 0 & 0 & 0
\end{array}\right]
$$$$
K_{R 3}^{n}=K_{r p}\left[\begin{array}{cccccc}
\sin ^{2}\left(\alpha_{c}\right) & -\varepsilon \sin \left(\alpha_{c}\right) \cos \left(\alpha_{c}\right) & 0 & -\frac{\varepsilon}{R b_{P}} \cos \left(\alpha_{c}\right) \sin \left(\alpha_{c}\right) & \frac{1}{R b_{P}} \sin \left(\alpha_{c}\right) \sin \left(\alpha_{c}\right) & -\varepsilon \sin \left(\alpha_{c}\right) \\
-\varepsilon \cos \left(\alpha_{c}\right) \sin \left(\alpha_{c}\right) & \varepsilon^{2} \cos ^{2}\left(\alpha_{c}\right) & 0 & \frac{\varepsilon^{2}}{R b_{P}} \sin \left(\alpha_{c}\right) \cos \left(\alpha_{c}\right) & -\frac{\varepsilon}{R b_{P}} \sin \left(\alpha_{c}\right) \cos \left(\alpha_{c}\right) & \varepsilon^{2} \cos \left(\alpha_{c}\right) \\
0 & 0 & 0 & 0 & 0 & 0 \\
-\frac{\varepsilon}{R b_{P}} \cos \left(\alpha_{c}\right) \sin \left(\alpha_{c}\right) & \frac{\varepsilon^{2}}{R b_{P}} \cos \left(\alpha_{c}\right) \cos \left(\alpha_{c}\right) & 0 & \frac{\varepsilon^{2}}{\left(R b_{P}\right)^{2}} \cos ^{2}\left(\alpha_{c}\right) & -\frac{\varepsilon}{\left(R b_{P}\right)^{2}} \sin \left(\alpha_{c}\right) \cos \left(\alpha_{c}\right) & \frac{\varepsilon^{2}}{R b_{P}} \cos \left(\alpha_{c}\right) \\
\frac{1}{R b_{P}} \sin \left(\alpha_{c}\right) \sin \left(\alpha_{c}\right) & -\frac{\varepsilon}{R b_{P}} \sin \left(\alpha_{c}\right) \cos \left(\alpha_{c}\right) & 0 & -\frac{\varepsilon}{\left(R b_{P}\right)^{2}} \sin \left(\alpha_{c}\right) \cos \left(\alpha_{c}\right) & \frac{1}{\left(R b_{P}\right)^{2}} \sin ^{2}\left(\alpha_{c}\right) & -\frac{\varepsilon}{R b_{P}} \sin \left(\alpha_{c}\right) \\
-\varepsilon \sin \left(\alpha_{c}\right) & \varepsilon^{2} \cos \left(\alpha_{c}\right) & 0 & \frac{\varepsilon^{2}}{R b_{P}} \cos \left(\alpha_{c}\right) & -\frac{\varepsilon}{R b_{P}} \sin \left(\alpha_{c}\right) & \varepsilon^{2}
\end{array}\right]
$$

$$
K_{S 3}^{n}=K_{s p}\left[\begin{array}{cccccc}
\sin ^{2}\left(\alpha_{s}\right) & \varepsilon \sin \left(\alpha_{s}\right) \cos \left(\alpha_{s}\right) & 0 & -\frac{\varepsilon}{R b_{P}} \cos \left(\alpha_{s}\right) \sin \left(\alpha_{s}\right) & -\sin \left(\alpha_{s}\right) & -\varepsilon \sin \left(\alpha_{s}\right) \\
\varepsilon \sin \left(\alpha_{s}\right) \cos \left(\alpha_{s}\right) & \varepsilon^{2} \cos ^{2}\left(\alpha_{s}\right) & 0 & -\frac{\varepsilon^{2}}{R b_{P}} \cos \left(\alpha_{s}\right) \cos \left(\alpha_{s}\right) & -\frac{\varepsilon}{R b_{P}} \sin \left(\alpha_{s}\right) \cos \left(\alpha_{s}\right) & -\varepsilon^{2} \cos \left(\alpha_{s}\right) \\
0 & 0 & 0 & 0 & 0 \\
-\frac{\varepsilon}{R b_{P}} \cos \left(\alpha_{s}\right) \sin \left(\alpha_{s}\right) & -\frac{\varepsilon^{2}}{R b_{P}} \cos \left(\alpha_{s}\right) \cos \left(\alpha_{s}\right) & 0 & \frac{\varepsilon^{2}}{\left(R b_{P}\right)^{2}} \cos ^{2}\left(\alpha_{s}\right) & -\frac{1}{R b_{P}} \frac{\varepsilon}{R b_{P}} \sin \left(\alpha_{s}\right) \cos \left(\alpha_{s}\right) & \frac{\varepsilon^{2}}{R b_{P}} \cos \left(\alpha_{s}\right) \\
-\sin \left(\alpha_{s}\right) & -\frac{\varepsilon}{R b_{P}} \sin \left(\alpha_{s}\right) \cos \left(\alpha_{s}\right) & 0 & -\frac{\varepsilon}{\left(R b_{P}\right)^{2}} \sin \left(\alpha_{s}\right) \cos \left(\alpha_{s}\right) & \frac{1}{\left(R b_{P}\right)^{2}} \sin ^{2}\left(\alpha_{s}\right) & -\frac{\varepsilon}{R b_{P}} \sin \left(\alpha_{s}\right) \\
-\varepsilon \sin \left(\alpha_{s}\right) & -\varepsilon^{2} \cos \left(\alpha_{s}\right) & 0 & \frac{\varepsilon^{2}}{R b_{P}} \cos \left(\alpha_{s}\right) & -\frac{\varepsilon}{R b_{P}} \sin \left(\alpha_{s}\right) & \varepsilon^{2}
\end{array}\right]
$$

\section{References}

[1] Cunliffe F., Smith J.D., Welbourn D.B., 1974, Dynamic tooth loads in epicyclic gears, Journal of Engineering for Industry, 95, 578-584

[2] LinJ., ParkerR.G., Sensitivity of planetary gear natural frequencies and vibration modes to model parameters, J. Sound Vib. 228 (1999) 109-128.

[3]AugustR., KasubaR., Torsional vibrations and dynamic loads in a basic planetary gear system, Journal ofVibration, Acoustics, Stressand Reliability in Design 108 (1986)348-353. 
[4] AbousleimanV., VelexP., A hybrid 3d finite element/lumped parameter model for quasi-static and dynamic analyses of planetary/epicyclic gear sets, Mechanism and Machine Theory, 41 (2006) 725 - 748

[5]AmbarishaV.K., Parker R.G., Non linear dynamics of planetary gears using analytical and finite element models, Journal of Sound and Vibration, 302 (2007) 577595

[6] LinJ., ParkerR.G., Structured vibration characteristics of planetary gears with unequally spaced planets, Journal of Sound and Vibration,233 (2000) 921-928.

[7] HammamiA., FernandezA., ChaariF., ViaderoF., HaddarM., modal analysis of back-to-back planetary gear: experiments and correlation against lumped-parameter model, Journal of Theoretical and Applied Mechanics 53, 1, (2015) 125-138

[8] EritenelT., ParkerR.G., Modal properties of three-dimensional helical planetary gears, Journal of Sound and Vibration,325 (2009) 397-420.

[9] GuoY., ParkerR.G., Dynamic analysis of planetary gears with bearing clearance, J. Comput. NonlinearDyn. 7 (2012) 041002.

[10] SunT., HuH., Nonlinear dynamics of a planetary gear system with multiple clearances, Mech. Mach. Theory 38 (2003) 1371-1390.

[11] CooleyC.G., ParkerR.G., Vibration properties of high-speed planetary gears with gyroscopic effects, J. Vib. Acoust. 134 (2012) 061014.

[12] Cooley C.G., ParkerR.G., 2013, Mechanical stability of high-speed planetary gears, International Journal of Mechanical Sciences, 69 (2013) 59-71

[13] ChaariF., AbbesM. S., Viadero F., Fernandez A., HaddarM., Analysis ofplanetary gear transmission in non-stationary operations, Frontiers Mechanical Engineering, 8(2013) 88-94

[14] HammamiA., FernandezA., ChaariF., ViaderoF., HaddarM., Dynamic behaviour of backto-back planetary gear in run up and run down transient regimes, Journal of Mechanics, 2015,31 (4) 481-491

[15]KahramanA.,Naturalmodesofplanetarygear trains, Journal ofSoundandVibration 173 (1994)125-130.

[16]VelexP.,FlamandL., Dynamic Response of Planetary Trains to MestiMesh Parametric Excitations,J.Mech.Des.118(1996)7-14

[17]Gelman L., Piecewise model and estimates of damping and natural frequency for a spur gear,Mechanical Systems and Signal Processing,Volume 21, Issue 2, February 2007, Pages21 (2007)1192-1196 
[18]Ericson T.M., Parker R.G., 2013, Planetary gear modal vibration experiments and correlation against lumped-parameter and finite element models, Journal of Sound and Vibration, 332 (2013) 2350-237

[19] KahramanA., VijayakarS.M., Effect of internal gear flexibility on the quasi-static behavior of a planetary gear set, J. Mech. Des. 123 (2001) 408-415.

[20] Toda A., Botman M., 1979, Planet indexing in planetary gears for minimum vibration, ASMEDesign Engineering Technical Conference, 1979, A80-15730, ASME, St. Louis

[22]HammamiA., FernandezA., ChaariF., ViaderoF., Haddar M., Dynamic behavior of back-to-back planetary gear in run up and run down transient regimes J. Mech., 31 (4) (2015), pp. 481-491

[23]Hammami-A., Fernandez A., Chaari F., Iglesias M., Viadero F., Haddar M.,Effects of variable loading conditions on the dynamic behavior of planetary gear with power recirculation.,Measurement 94 (2016)306-315

[21]Ericson T.M., Parker R.G.Experimental measurement of the effects of torque on the dynamic behavior and system parameters of planetary gears, Mechanism and Machine Theory 74 (2014) 370-389

[24]Karray M., Feki N., Khabou M.T., Chaari F., Haddar M., Modal analysis of gearbox transmission system in Bucket wheel excavator,Journal of theoretical and applied mechanics 55, 1, pp. 253-264, Warsaw 2017 DOI: 10.15632/jtam-pl.55.1.253 [25] A. Fernandez del Rincon, F. Viadero, M. Iglesias, P. García, A. de-Juan, R. Sancibrian, A model for the study of meshing stiffness in spur gear transmissions, Mechanism and Machine Theory 61 (2013) 30-58 